W. H. Wagner, A father's fate. Attitudes toward and interpretations of Clement of Alexandria, Journal of Religious History (Sydney) 6, 1971, 209-231.

G. Zaphiris, Le texte de l'Évangile selon saint Matthieu d'après les citations de Clément d'Alexandrie comparées aux citations des Pères et des théologiens grecs du $\mathrm{II}^{\mathrm{e}}$ au XVe siècle, Gembloux 1970.

\title{
LITERATUR UND ADDENDA ZU BAND I
}

Clemente Alessandrino, Il Protrettico, il Pedagogo. Introduzione, traduzione e commentario a cura di M. G. Bianco, Torino 1971 (Classici delle religioni. Sezione IV, La religione cattolica).

Paidagogos: Ausgewählte Schriften zur Pädagogik, besorgt von H. Kanz, Paderborn 1966.

G. Brambillasca, Citations de l'Écriture Sainte et des auteurs classiques dans le

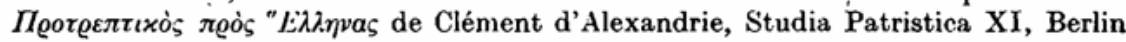
1972 (TU 108), 8-12.

A. H. C. van Eijk, The Gospel of Philip and Clement of Alexandria. Gnostic and ecclesiastical theology on the resurrection and the eucharist, Vigiliae Christianae 25, 1971, 94-120.

L. Alfonsi, Uno spunto posidiano in Clemente Alessandrino, in: Romanitas et Christianitas. Studia 1. H. Waszink oblata. Amsterdam 1973, 1-3.

7, 13-20 erhalten als Zitat im Cod. Ohrid, Nationalmuseum 84 (Mošin), 13. Jh.,

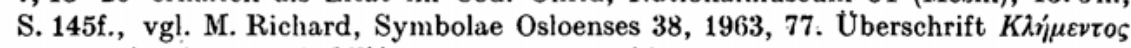

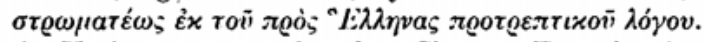

An Varianten gegenüber dem Clemens-Text der Ausgabe sind zu verzeichnen:

$\left.\left.13 \delta \iota^{\prime} \quad \ddot{v} v\right] \delta \iota \dot{o} \quad \vartheta \varepsilon o \bar{v}\right] \vartheta \varepsilon i o v 0$

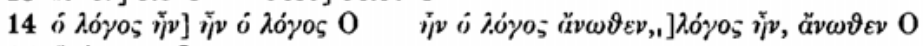

15 veía om. O

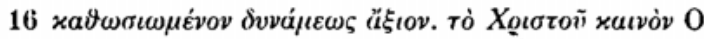

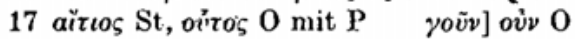

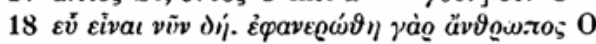

19 á $\pi \dot{\nu} \nu \tau \nu]$ ó $\pi \dot{\alpha} \nu \tau \omega \nu 0$

$51,10 \mathrm{vgl}$. L. Piccirilli, Susarione e la rivendicazione megarese dell'Origine della commedia greca, Annali della Scuola Normale Superiore di Pisa 4, 1974, 1289-1299.

61 vgl. F. J. Dölger, Das Sonnengleichnis in einer Weihnachtspredigt des Bischofs Zeno von Verona, Antike und Christentum 6, 1940, 4 u. ö.

68, 17 vgl. Q. Cataudella, Kahò $\dot{0}$ ※ivovvo , Sileno 1, Catania 1975, 23-36.

$68,19 f$. vgl. M. Tardieu, La lettre à Hipparque et les réminiscences pythagoriciennes de Clément d'Alexandrie, Vigiliae Christianae 28, 1974, 241-247, hier 246.

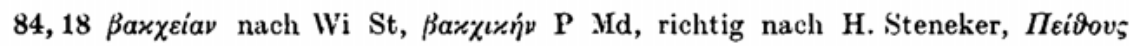




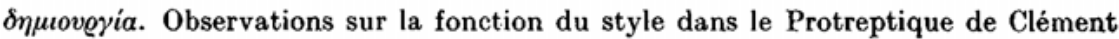
d'Alexandrie, Nymwegen 1967 (Graecitas Christianorum Primaeva 3), XXIV, 174.

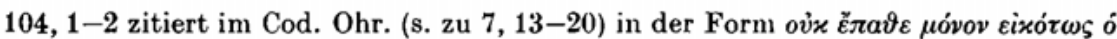

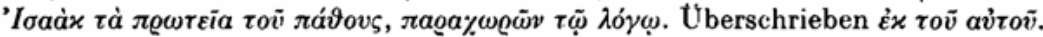

173, 14ff. vgl. Tardieu 245.

186, 12f. Zitat aus den Apokryphon des Ezechiel? (Denis, Introduction, 189f.).

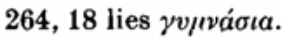

278, 31 vgl. Plut. Quaest. conviv. 7, 8, 4 (Hinweis von W.Weismann, Kirche und Schauspiele, IVürzburg 1972, 73, Anm. 21).

\section{LITERATUR UND ADDENDA ZU BAND II}

F. Bolgiani, La polemica di Clemente Alessandrino contro gli gnostici libertini nel III libro degli Stromati, Studi e materiali di storia delle religioni 38, 1967, 86-136.

C. Del Grande, Brevi note al testo del primo Stromate di Clemente Alessandrino, Rivista indo-greco-italica $18,1934,152-158$.

A. Hirner, Die Stromata des Clemens von Alexandrien, Paradigma für die mediale Bedeutung der Philosophie zur Entfaltung christlicher Lehre. Ein Beitrag zum Diastasenproblem, Diss. Innsbruck 1970 (Maschinenschrift).

G. Lazzati, Aevum 9, 1935, 565-569.

G. Lazzati, Introduzione allo studio di Clemente Alessandrino, Milano 1939 (darin S. 73-92: Note critiche).

A. Méhat, Remarques sur quelques passages du Ile Stromate de Clément d'Alexandrie, Revue des études grecques $69,1956,41-49$.

A. Méhat, L'hypothèse des Testimonia à l'épreuve des Stromates. Remarques sur les citations de l'Ancien Testament chez Clément d'Alexandrie, in: La Bible et les Pères, Colloque de Strasbourg 1969, Strasbourg-Paris 1971, 229-242.

A. Méhat, Clément d'Alexandrie et le sens de l'Écriture, Ier Stromate, 176, 1 et 179, 3, in: Epektasis, Mélanges Jean Daniélou, Paris 1972, 35j-365.

P. Nautin, Notes sur le Stromate I de Clément d'Alexandrie, Revue d'histoire ecclésiastique 47, 1952, 618-631. 641.

P. Nautin, Notes eritiques sur le Stromate Il de Clément d'Alexandrie, Revue d'histoire ecclésiastique $49,1954,835-841$. 887-890.

H.-R. Schwyzer, (inomon 37, 1965, 484-490 (Rez. zu Band II).

$3 \mathrm{ff}$. Dazu M. F. Osborne, Teaching and writing in the first chapter of the Stromateis of Clement of Alexandria, Journal of Theological Studies N. S. 10, 1959, 335-343.

13, 17 vgl. Philo, de migr. Abr. 15; auch Min. Fel. 27, 2. 